10

\title{
Аномалии в стехиометрическом кристалле ниобата лития в диапазоне температур 100-400 K
}

\author{
(C) Н.В. Сидоров, В.А. Сандлер, М.Н. Палатников \\ Институт химии и технологии редких элементов и минерального сырья им. И.В. Тананаева Федерального \\ исследовательского центра „Кольский научный центр Российской академии наук“, \\ 184209 Апатиты, Мурманская обл., Россия \\ e-mail: n.sidorov@ksc.ru
}

Поступила в редакцию 04.12.2020 г.

В окончательной редакции 04.12.2020 г.

Принята к публикации 16.02.2021 г.

Показано, что различия в аномальном температурном поведении термолюминесценции и интенсивностей линий в спектрах комбинационного рассеяния света конгруэнтного и стехиометрического кристаллов ниобата лития обусловлены разным температурным поведением различных типов электронных ловушек и различием в величине релеевского фотоиндуцированного рассеяния света в этих кристаллах.

Ключевые слова: стехиометрический и конгруэнтный кристаллы ниобата лития, комбинационное и фотоиндуцированное рассеяние света, термолиз мелких электронных ловушек.

DOI: $10.21883 /$ OS.2021.06.50991.301-20

\section{Введение}

Обычно аномалии в температурном поведении физических характеристик сегнетоэлектрических кристаллов наблюдаются вблизи точек структурных фазовых переходов и связаны с неустойчивостью кристаллической решетки по некоторым ее параметрам [1]. Однако для нелинейно-оптических кристаллов ниобата лития $\left(\mathrm{LiNbO}_{3}\right)$, номинально чистых (с разным отношением $\mathrm{Li} / \mathrm{Nb}$ ) и легированных, при существенно более низких температурах, чем точка сегнетоэлектрического фазового перехода $(\sim 1483 \mathrm{~K})$, в диапазоне $200-400 \mathrm{~K}$ наблюдаются аномалии в температурном поведении проводимости, оптических, нелинейно-оптических, диэлектрических, пьезоэлектрических, пироэлектрических характеристик, зависящие от состава и генезиса кристалла [2-13]. Наличие аномалий часто бывают причиной того, что для некоторых важных оптических приложений кристалл $\mathrm{LiNbO}_{3}$, несмотря на уникальные физические характеристики (высокие значения температуры Кюри, спонтанной поляризации, электрооптических коэффициентов и др.), считается „грязным“ материалом. Выявление и установление механизмов образования аномалий в кристаллах $\mathrm{LiNbO}_{3}$ разного состава в практически значимом диапазоне температур 200-400 К является актуальным для устранения причин нестабильности физических характеристик и отработки технологий высокосовершенных нелинейно-оптических материалов на основе монокристалла $\mathrm{LiNbO}_{3}$. Особый интерес представляют исследования аномалий в кристаллах стехиометрического состава $(R=\mathrm{Li} / \mathrm{Nb}=1)$, которые в виду гораздо более низкого значения напряженности коэрцитивного поля по сравнению с кристаллами других составов $(\sim 3 \mathrm{kV} / \mathrm{cm}$ и $\sim 20-23 \mathrm{kV} / \mathrm{cm})[14,15]$ в настоящее время наиболее перспективны для создания высокосовершенных материалов для преобразования лазерного излучения на периодически поляризованных доменах субмикронных размеров $[16,17]$.

Известно, что повышение температуры от азотной до комнатной для большинства сегнетоэлектрических кристаллов приводит к тушению термостимулированной люминесценции в ближнем ультрафиолете и видимой области спектра [13]. Для кристалла $\mathrm{LiNbO}_{3}$ любого состава повышение температуры до $400 \mathrm{~K}$, кроме того, приводит к уменьшению до нуля эффекта фотоиндуцированного изменения показателя преломления [18-20] и к увеличению проводимости [6,8]. Эти факты позволяют предположить, что аномалии в диапазоне $200-400 \mathrm{~K}$ могут быть обусловлены перестройкой в кристалле $\mathrm{LiNbO}_{3}$ при изменении температуры сложной системы неравновесных дефектов с локализованными на них носителями зарядов (собственных, примесных, технологических [18-24]), характерных для фоторефрактивного кристалла $\mathrm{LiNbO}_{3}$ как гетеродесмической кислороднооктаэдрической фазы переменного состава. При перестройке системы заряженных дефектов в фоторефрактивном кристалле $\mathrm{LiNbO}_{3}$ происходят изменения внутренних электрических полей $[19,20]$, что может вызвать изменения поляризуемости межатомных связей, принимающих участие в колебании, и изменение поляризуемости элементарной ячейки в целом. Изменение поляризуемости приводит к изменению интенсивностей линий в фононном спектре [19]. Уместно также отметить, что неравновесные дефекты создают существенно зависящие от состава кристалла и температуры многочисленные мелкие уровни в запрещенной зоне вблизи дна зоны проводимости, определяющие характер термолюминесценции [24-26]. Процессы термолюминесценции способны 
конкурировать с процессами захвата носителей заряда глубокими электронными ловушками и наряду с ними влиять на фоторефрактивные свойства кристалла.

В работе [7] обнаружено и кратко обсуждается, не вдаваясь в механизм явления, аномальное поведение с температурой в диапазоне $100-440 \mathrm{~K}$ интенсивностей линий в фононном спектре комбинационного рассеяния света (КРС) кристаллов $\mathrm{LiNbO}_{3}$ конгруэнтного ( $\left.\mathrm{LiNbO}_{3 \text { cong }}, R=0.946\right)$ и стехиометрического $\left(\mathrm{LiNbO}_{3 \text { stoich }}\right)$ составов. В настоящей работе представлены более полные результаты сравнительных исследований фононного спектра КРС, низкотемпературной термолюминесценции (возникающей без воздействия лазерного излучения) кристаллов $\mathrm{LiNbO}_{3 \text { stoich }}$ и $\mathrm{LiNbO}_{3 \text { cong }}$ и сделан подробный анализ причин существенно более аномального температурного поведения в диапазоне $100-440 \mathrm{~K}$ интенсивностей линий в спектре КРС кристалла $\mathrm{LiNbO}_{3 \text { stoich }}$ по сравнению с кристаллом $\mathrm{LiNbO}_{3 \text { cong }}$.

Стехиометрический и конгруэнтный кристаллы $\mathrm{LiNbO}_{3}$ существенно отличаются микроструктурой, особенностями упорядочения структурных единиц катионной подрешетки вдоль полярной оси, концентрацией и типом неравновесных дефектов в виде мелких и глубоких электронных ловушек, особенностями расположения энергетических уровней в запрещенной зоне, степенью деформации кислороднооктаэдрических кластеров $\mathrm{NbO}_{6}[15,18-26]$.

\section{Методика эксперимента}

Кристаллы $\mathrm{LiNbO}_{3 \text { stoich }}$ и $\mathrm{LiNbO}_{3 \text { cong }}$ выращивались соответственно из расплава с $58.6 \mathrm{~mol} \%$ Li2O и из конгруэнтного расплава $(R=0.946)$. Образцы для исследований вырезались в виде прямоугольных параллелепипедов размерами $\sim 4 \times 5 \times 7 \mathrm{~mm}$, ребра которых совпадали с направлением кристаллографических осей $X, Y, Z$. Грани параллелепипедов тщательно полировались. Подробно получение шихты и кристаллов, их подготовка для исследований, включая высокотемпературную монодоменизацию, описаны работах [7,14,27-29]. Интегральные характеристики низкотемпературной термолюминесценции были исследованы в режиме линейного нагрева образцов в диапазоне $80-270 \mathrm{~K}$ без воздействия лазерного излучения с использованием оригинальной экспериментальной установки.

Приемником излучения служил ФЭУ SRJ-100. Peгистрация температурных зависимостей интенсивности свечения осуществлялась с помощью многоканального АЦП ZetLab 220, связанного с компьютером. Система управления температурой выполнена на основе программного регулятора Термодат-19E с использованием распределённого Pt-термометра в обратной связи. Спектры КРС возбуждались линией $514.5 \mathrm{~nm}$ аргонового лазера Spectra Physics (модель 2018-RM) и регистрировались спектрографом Т64000 производства фирмы Horiba
Jobin Yvon с использованием конфокального микроскопа и термокамеры Linkam THMS600.

Обработка спектров производилась с использованием пакета программ Horiba LabSpec 5.0 и Origin 8.1. Точность определения интенсивностей линий 5\%. Для исследований кристаллов методом фотоиндуцированного рассеяния света (ФИРС) использовался Nd:YAG-лазер (MLL-100), $\lambda_{0}=532 \mathrm{~nm}$. Экспериментальная установка описана в работе [29].

\section{Результаты и их обсуждение}

На рис. 1 приведены температурные зависимости интенсивностей линий в спектре КРС кристаллов $\mathrm{LiNbO}_{3 \text { cong }}$ и $\mathrm{LiNbO}_{3 \text { stoich, }}$ соответствующих фононам $A_{1}(\mathrm{TO})$ - и $E(\mathrm{TO})$-типа симметрии и интегральной термолюминесценции этих же кристаллов. Видно, что для кристалла $\mathrm{LiNbO}_{3 \text { stoich }}$ в температурной зависимости интенсивностей практически всех линий наблюдается глубокий и широкий минимум в диапазоне $120-380 \mathrm{~K}$. В то же время для кристалла $\mathrm{LiNbO}_{3 \text { cong }}$ таких глубоких аномалий не обнаружено. Особенности температурной зависимости термолюминесценции кристаллов $\mathrm{LiNbO}_{3 \text { stoich }}$ и $\mathrm{LiNbO}_{3 \text { cong }}$ также существенно различаются (рис. 1). Минимум в температурной зависимости интенсивностей линий в спектре КРС кристаллов $\mathrm{LiNbO}_{3 \text { cong }}$ и $\mathrm{LiNbO}_{3 \text { stoich }}$ наиболее сильно проявляется для линии с частотой $255 \mathrm{~cm}^{-1}(T=293 \mathrm{~K})$, соответствующей сильно смешанным ангармоничным фундаментальным колебаниям $A_{1}(\mathrm{TO})$-типа симметрии внутриоктаэдрических ионов $\mathrm{Nb}^{5+}$ (квазимягкая мода) и ионов $\mathrm{O}^{2-}$, происходящим преимущественно вдоль полярной оси [19,30-32]. Уместно отметить, что смещение иона $\mathrm{Nb}^{5+}$ из центра октаэдра вдоль полярной оси приводит к возникновению спонтанной поляризации и сегнетоэлектричества в кристалле $\mathrm{LiNbO}_{3}[18,19]$.

Из рис. 1 видно также, что в спектре кристалла $\mathrm{LiNbO}_{3 \text { cong }}$ интенсивности линий, соответствующих колебаниям $E(\mathrm{TO})$-типа симметрии, происходящих преимущественно перпендикулярно полярной оси [30,31], с изменением температуры практически не изменяются. Совсем иная ситуация наблюдается для кристалла $\mathrm{LiNbO}_{3 \text { stoich, }}$ в котором практически отсутствуют дефекты NbLi, но при этом существует более развитая система неравновесных дефектов, чем в кристалле $\mathrm{LiNbO}_{3 \text { cong }}[15,19,33]$. В спектре кристалла $\mathrm{LiNbO}_{3 \text { stoich }} \mathrm{c}$ изменением температуры наблюдается аномальное поведение интенсивности практически всех линий, соответствующих как фононам $A_{1}(\mathrm{TO})$-, так и фононам $E(\mathrm{TO})$ типа симметрии. При этом температурная зависимость интенсивности линии, отвечающей полносимметричным колебаниям кислородных октаэдров $A_{1}(\mathrm{TO})$-типа симметрии $\left(630 \mathrm{~cm}^{-1}, T=293 \mathrm{~K}\right.$, „дышащая мода“" $)$, в спектре кристалла $\mathrm{LiNbO}_{3 \text { stoich }}$ не испытывает аномалий. Для кристалла $\mathrm{LiNbO}_{3 \text { stoich }}$ аномалии минимальны также для температурного поведения интенсивности линии с 

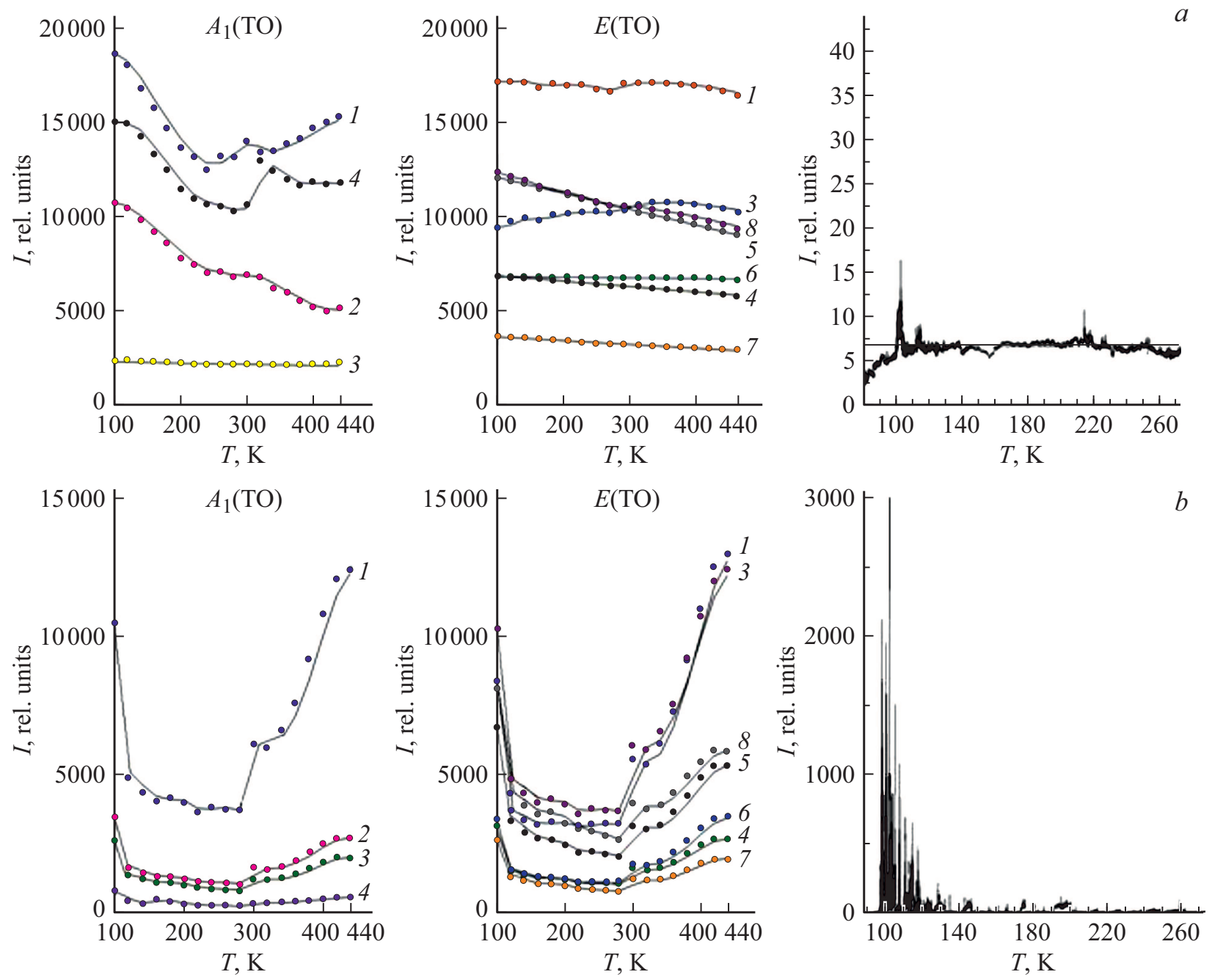

Рис. 1. Температурные зависимости интенсивностей линий спектра КРС, соответствующих фундаментальным колебаниям решетки $A_{1}(\mathrm{TO})$ - и $E(\mathrm{TO})$-типов симметрии и термолюминесценции кристаллов $\mathrm{LiNbO}_{3 \text { cong }}(a)$ и $\mathrm{LiNbO}_{3 \text { stoich }}(b)$. Колебания $A_{1}(\mathrm{TO})$-типа симметрии: $1-2741 A_{1}(\mathrm{TO}), 2-3332 A_{1}(\mathrm{TO}), 3-4323 A_{1}(\mathrm{TO}), 4-8754 A_{1}(\mathrm{TO}) \mathrm{cm}^{-1}$. Колебания $E(\mathrm{TO})$-типа симметрии: $1-1521 E(\mathrm{TO}), 3-2373 E(\mathrm{TO}), 4-2624 E(\mathrm{TO}), 5-3225 E(\mathrm{TO}), 6-3686 E(\mathrm{TO}), 7-4357 E(\mathrm{TO}), 8-579$ $8 E(\mathrm{TO}) \mathrm{cm}^{-1} . T=293 \mathrm{~K}$. Здесь приведены общепринятые порядковые номера колебаний $A_{1}(\mathrm{TO})$ и $E(\mathrm{TO})[19,32]$. Малоинтенсивная линия с частотой $180 \mathrm{~cm}^{-1} 2 E(\mathrm{TO})$ проявляется только в спектре высокоупорядоченного стехиометрического кристалла [19] и расположена на фоне очень интенсивных линий с частотами 152 и $237 \mathrm{~cm}^{-1}$. По этим причинам измерить корректно температурное поведение ее интенсивности невозможно.

частотой $580 \mathrm{~cm}^{-1}$, соответствующей дважды вырожденным колебаниям кислородных октаэдров $\mathrm{O}_{6} E(\mathrm{TO})$-типа симметрии. Эти факты свидетельствуют о более высокой устойчивости к воздействию температуры кислородных октаэдров $\mathrm{O}_{6}$ стехиометрического кристалла по сравнению с конгруэнтным. Однако при этом кислороднооктаэдрические кластеры $\mathrm{NbO}_{6}$, определяющие спонтанную поляризацию и поляризуемость элементарной ячейки, а следовательно, сегнетоэлектрические и нелинейнооптические свойства кристалла, подвержены температурному воздействию.

Согласно данным многочисленных исследований конгруэнтных кристаллов $\mathrm{LiNbO}_{3}$, номинально чистых и легированных (обзоры даны в работах [7,14,18-20,32,33]), параметры элементарной ячейки, координаты атомов и частоты линий в спектре КРС, соответствующих фундаментальным колебаниям решетки, в диапазоне температур 100- $450 \mathrm{~K}$ не испытывают аномалий. Температурные зависимости ширин и частот всех линий в спектре КРС исследованных нами кристаллов $\mathrm{LiNbO}_{3 \text { cong }}$ и $\mathrm{LiNbO}_{3 \text { stoich, }}$ соответствующих фундаментальным колебаниям решетки, также не испытывают аномалий в температурном интервале $100-440 \mathrm{~K}$ [7]. Эти факты свидетельствуют о высокой устойчивости основной структуры кристалла (прежде всего координат основных ионов $\mathrm{Li}^{+}$, $\left.\mathrm{Nb}^{5+}, \mathrm{O}^{2-}\right)$ к воздействию температуры в интервале $100-450 \mathrm{~K}$. Таким образом, причины аномалий в температурном поведении интенсивностей линий в спектре КРС следует искать в особенностях температурной перестройки системы неравновесных дефектов кристалла 
$\mathrm{LiNbO}_{3}$. Необходимо отметить, что в стехиометрическом кристалле подрешетка неравновесных дефектов (мелких электронных ловушек) существенно „богаче“, чем в конгруэнтном [19-21]. Кроме того, стехиометрический состав, согласно фазовой диаграмме, при температурах ниже $400 \mathrm{~K}$ находится на границе области гомогенности и является метастабильным [18,19,34].

В аномальное температурное поведение интенсивностей линий в спектре КРС кристалла $\mathrm{LiNbO}_{3}$ могут внести вклад в основном три фактора, зависящие от температуры: эффект фоторефракции, домены и микроструктурированность кристалла, а также неравновесные дефекты, ответственные за термолюминесценцию.

Домены, кластеры и микроструктуры, обладающие собственной структурой, составом, размерами и четко выделенными границами, являются важной особенностью вторичной структуры кристалла $\mathrm{LiNbO}_{3}[6,8,16,22]$. На их границах может происходить интенсивное рассеяние и деполяризация возбуждающего лазерного излучения, которые могут влиять на вид спектра КРС в поляризованном излучении. При этом доля релеевского рассеянного излучения на границах и интенсивность линий в спектре КРС могут изменяться при изменении границ доменов, кластеров и микроструктур. Однако для кристалла ниобата лития изменения границ доменов в диапазоне $100-450 \mathrm{~K}$ представляются маловероятными ввиду высокой энергии активации границ $[4,6,10]$. Необходимо отметить и то, что мы исследовали монодоменизированные образцы. Таким образом, для диапазона температур $100-450 \mathrm{~K}$ для кристалла $\mathrm{LiNbO}_{3}$ вклад в изменение интенсивности рассеянного возбуждающего лазерного излучения и соответственно в изменение интенсивности линий в спектре КРС за счет изменения доменных границ будет постоянным с температурой и незначительным по величине.

В кристалле $\mathrm{LiNbO}_{3}$ под действием лазерного излучения происходят различные фотоиндуцированные процессы, связанные с пространственным разделением зарядов и возникновением фотоэлектрических полей (фотовольтаического $E_{P V}$ и диффузионного $E_{D}$ ), которые приводят к образованию многочисленных лазерноиндуцированных дефектов, к существенной деструкции возбуждающего спектр КРС лазерного луча в кристалле $[14,19,29,35-40]$ (рис. 2). Напряженность диффузионного поля в кристалле $\mathrm{LiNbO}_{3 \text { stoich }}$ составляет $1360 \mathrm{~V} / \mathrm{cm}$, в то время как в кристалле $\mathrm{LiNbO}_{3 \text { cong }}$ только $104 \mathrm{~V} / \mathrm{cm}$ [35]. Этот факт подтверждает большую концентрацию неравновесных дефектов в кристалле

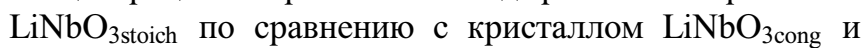
свидетельствует о том, что в кристалле $\mathrm{LiNbO}_{3 \text { stoich }}$ более сильно проявляется диффузионный механизм переноса заряда, чем в кристалле $\mathrm{LiNbO}_{3 \text { cong. Лазерно- }}$ индуцированные и термостимулированные дефекты находятся в неравновесном состоянии, поэтому они наиболее чувствительны к изменению температуры кристалла.

На рис. 2 показаны индикатрисы спекл-структуры ФИРС для кристаллов $\mathrm{LiNbO}_{3 \text { stoich }}$ и $\mathrm{LiNbO}_{3 \text { cong. От- }}$
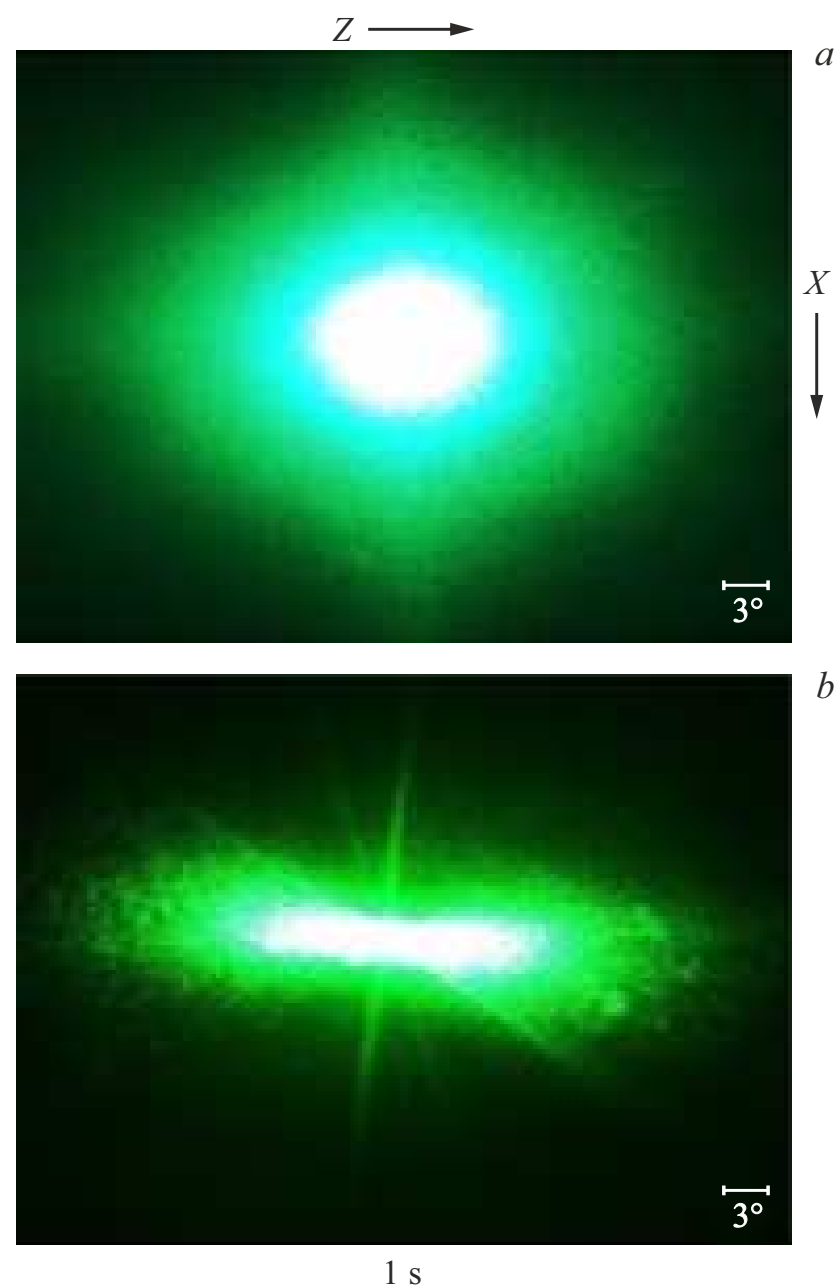

Рис. 2. Прохождение поляризованного лазерного излучения через кристаллы $\mathrm{LiNbO}_{3 \text { cong }}(a)$ и $\mathrm{LiNbO}_{3 \text { stoich }}(b)$. Отчетливо видно фотоиндуцированное рассеяние света $e e$-типа [38] и деструкция лазерного луча в кристалле $\mathrm{LiNbO}_{3 \text { stoich. }} Z$ - полярная ось кристалла. $\lambda_{0}=514.5 \mathrm{~nm} . p=6.29 \mathrm{~W} / \mathrm{cm}^{2} . T=293 \mathrm{~K}$.

четливо видна деструкция лазерного луча в кристалле

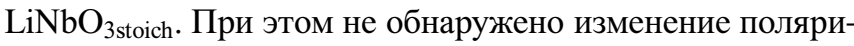
зации лазерного излучения, прошедшего через кристалл. В то же время при такой же плотности мощности возбуждающего лазерного излучения $\left(6.29 \mathrm{~W} / \mathrm{cm}^{2}\right)$ индикатриса ФИРС для кристалла $\mathrm{LiNbO}_{3 \text { cong }}$ не раскрывается, и наблюдается только круговое рассеяние на статических дефектах структуры кристалла. В кристалле $\mathrm{LiNbO}_{3 \text { cong }}$ раскрытие спекл-структуры индикатрисы ФИРС происходит при существенно большей плотности мощности возбуждающего лазерного излучения, чем в

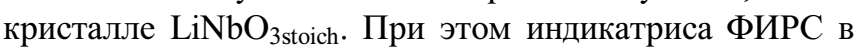
кристаллах $\mathrm{LiNbO}_{3 \text { stoich }}$ и $\mathrm{LiNbO}_{3 \text { cong }}$ раскрывается за одинаковое время (около $60 \mathrm{~s}$ ), но особенности раскрытия различаются $[29,39]$.

С увеличением величины $R=\mathrm{Li} / \mathrm{Nb}$, т. е. с приближением состава кристалла к стехиометрическому $(R \rightarrow 1)$, количество дефектов $\mathrm{Nb}_{\mathrm{Li}}$ и связанных с ними глубо- 
ких уровней захвата в запрещенной зоне уменьшается. Но при этом вследствие сохранения электронейтральности кристалла одновременно увеличивается количество равновесных и неравновесных дефектов в виде мелких ловушек электронов, наиболее чувствительных к изменению температуры, что приводит к снижению энергетического порога для появления эффекта фоторефракции. Этим можно объяснить факт раскрытия спекл-структуры индикатрисы ФИРС в кристалле $\mathrm{LiNbO}_{3 \text { stoich }}$ при существенно меньшей плотности мощности возбуждающего лазерного излучения, чем в кристалле $\mathrm{LiNbO}_{3 \text { cong }}$ (рис. 2). С понижением температуры происходит „замораживание“ дефектов в виде мелких электронных ловушек, которых в кристалле $\mathrm{LiNbO}_{3 \text { stoich }}$

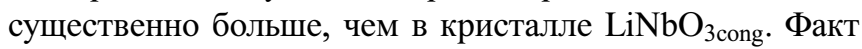
увеличения при понижении температуры количества „замороженных“ мелких фотоиндуцированных ловушек электронов в фоторефрактивном кристалле $\mathrm{LiNbO}_{3 \text { stoich }}$ подтверждают данные работы [41], в которой приведены результаты исследований влияния температуры на особенности дефокусировки лазерного луча, прошедшего через фоторефрактивный кристалл $\mathrm{LiNbO}_{3}: \mathrm{Fe}$, а также на фоторефрактивную неоднородность, создаваемую в кристалле лазерным лучом. Оказалось, что при азотных температурах фотоиндуцированная неоднородность кристалла $\mathrm{LiNbO}_{3}$ : Fe намного больше, чем при комнатной температуре. Это обусловлено тем, что при азотных температурах кристалл $\mathrm{LiNbO}_{3}: \mathrm{Fe}$, как и кристалл $\mathrm{LiNbO}_{3 \text { stoich, }}$ характеризуется наличием максимального количества „замороженных“ мелких ловушек электронов различного типа, и поэтому вероятность излучательной рекомбинации фотовозбужденных носителей заряда мала.

С этих позиций можно объяснить различия в аномальном поведении с температурой интенсивностей линий в спектре КРС кристалла $\mathrm{LiNbO}_{3 \text { stoich }}$ Резкое уменьшение интенсивности линий в спектре кристалла $\mathrm{LiNbO}_{3 \text { stoich }}$ в области температур 100-120 K (рис. 1) может быть обусловлено интенсивной перестройкой электронной подсистемы кристалла, вызванной термолизом мелких электронных ловушек с последующей излучательной рекомбинацией электрон-дырочных пар в этой области температур [26]. В то же время для кристалла $\mathrm{LiNbO}_{3 \text { cong, }}$ в котором количество мелких ловушек электронов существенно меньше, чем в кристалле $\mathrm{LiNbO}_{3 \text { stoich, этот }}$ эффект выражен гораздо слабее, что подтверждается данными термолюминесценции. В диапазоне температур $100-120 \mathrm{~K}$ для кристалла $\mathrm{LiNbO}_{3 \text { stoich }}$ в отличие от кристалла $\mathrm{LiNbO}_{3 \text { cong }}$ характерно наличие множества узких интенсивных линий термолюминесценции (рис. 1), связанных с термолизом мелких электронных ловушек и последующей излучательной рекомбинацией электрондырочных пар.

Необходимо отметить и следующий факт. Ширина запрещенной зоны $(3.48 \mathrm{eV})$ в кристалле $\mathrm{LiNbO}_{3 \text { stoich }}$ меньше, чем в кристалле $\mathrm{LiNbO}_{3 \text { cong }}(3.72 \mathrm{eV})$ [35]. При этом кристалл $\mathrm{LiNbO}_{3 \text { stoich }}$ характеризуется существенно большим количеством мелких электронных ловушек по

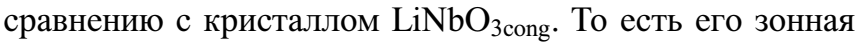
структура локально искажена более сильно и отличается гораздо большим количеством энергетических уровней $[25,35]$. Поэтому вероятность образования электрондырочных пар заметно больше в кристалле $\mathrm{LiNbO}_{3 \text { stoich, }}$

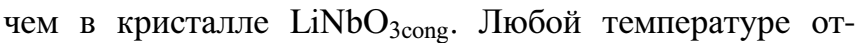
вечает равновесная концентрация электрон-дырочных пар [26]. Ясно, что при комнатной температуре она явно больше, чем при температуре жидкого азота. Значит, при охлаждении (даже без предварительного использования дополнительных источников энергии) может наблюдаться рекомбинация электрон-дырочных пар. В этом случае, если разрешены излучательные переходы, имеет место рекомбинационная люминесценция. При этом необходимо иметь в виду, что охлаждение приводит к заметному увеличению времени жизни неравновесного состояния (здесь - электрон-дырочных пар), поэтому при реальном времени измерений наблюдается свечение как при нагревании, так и при охлаждении (особенно быстром). Прямым подтверждением такой рекомбинации служит наличие коротких (по температуре) импульсов в температурной зависимости термолюминесценции, подобных квантованию энергии излучательных переходов (рис. 1).

Вследствие увеличения термолюминесценции и релеевского рассеяния на лазерно-индуцированных дефектах должно произойти уменьшение энергии, идущей на комбинационное рассеяние света. Этот процесс для кристаллов $\mathrm{LiNbO}_{3 \text { stoich }}$ и $\mathrm{LiNbO}_{3 \text { cong }}$ ввиду значительного различия их дефектной структуры существенно отличается. В структуре кристалла $\mathrm{LiNbO}_{3 \text { stoich }}$ присутствует гораздо больше фотоиндуцированных дефектов и дефектов в виде мелких электронных ловушек, чем в кристалле $\mathrm{LiNbO}_{3 \text { cong, }}$,оторые активно „залечиваются“ с повышением температуры, что приводит к отключению механизмов фоторефракции и уменьшению интенсивности релеевского рассеяния на фотоиндуцированных дефектах. Вследствие этого увеличивается доля энергии на

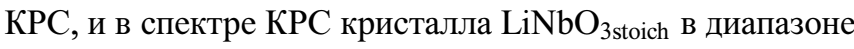
температур $\sim 300-400 \mathrm{~K}$ происходит достаточно резкий рост интенсивности линий, соответствующих фундаментальным колебаниям $A_{1}(\mathrm{TO})$ - и $E(\mathrm{TO})$-типов симметрии (рис. 1).

\section{Заключение}

Таким образом, различное аномальное температурное поведение интенсивностей линий в спектрах КРС кристаллов $\mathrm{LiNbO}_{3 \text { stoich }}$ и $\mathrm{LiNbO}_{3 \text { cong }}$ в диапазоне температур 100-440 K обусловлено разным типом преобладающих ловушек электронов в этих кристаллах и отличием в температурном поведении мелких и глубоких электронных ловушек. Резкое уменьшение интенсивности линий в спектре КРС кристалла $\mathrm{LiNbO}_{3 \text { stoich }}$ в области температур 100-120 К обусловлено интенсивной перестройкой электронной подсистемы кристалла, 
вызванной термолизом мелких электронных ловушек в этой области температур. При дальнейшем повышении температуры (в диапазоне температур 300-400 K) в кристалле $\mathrm{LiNbO}_{3 \text { stoich }}$ происходит активное ,залечивание“ дефектов в виде мелких электронных ловушек и „отключение“ соответствующих этим дефектам механизмов фоторефракции. Этот процесс сопровождается уменьшением доли релеевского рассеяния света и увеличением интенсивностей линий в спектре КРС кристалла

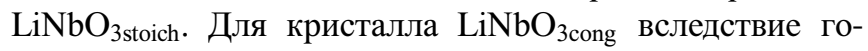
раздо меньшего количества мелких ловушек электронов по сравнению с кристаллом $\mathrm{LiNbO}_{3 \text { stoich такого резко- }}$ го изменения с температурой интенсивностей линий в спектре КРС, которое наблюдается для кристалла $\mathrm{LiNbO}_{3 \text { stoich, }}$ не происходит.

\section{Конфликт интересов}

Авторы заявляют, что у них нет конфликта интересов.

\section{Список литературы}

[1] Струков Б.А., Леванюк А.П. Физические основы сегнетоэлектрических явлений в кристаллах. М.: Наука, 1995. $238 \mathrm{c}$.

[2] Fernandes-Ruiz R., Martin D., Marero $Y$, Bermudez V. // Phys. Rev. B. 2005. V. 72. P. 184108-1. doi 10.1103/PhysRevB.72.184108

[3] Golubovic A., Gajic R., Hinic I., Valcic A. // J. Serb. Chem. Soc. 2004. V. 69. N 6. P. 493.

[4] Евдокимов С.В., Шостак Р.И., Яценко А.В. // ФТТ. 2007. T. 49. № 10. C. 1866; Yevdokimov S.V., Shostak R.I., Yatsenko A.V. // Phys. Sol. St. 2007. V. 49. N 10. P. 1957. doi $10.1134 / \mathrm{S} 1063783407100241$

[5] Шостак Р.И., Евдокимов С.В., Яценко А.В. // Кристаллогр. 2009. T. 54. № 3. C. 527; Shostak R.I., Yevdokimov S.V., Yatsenko A.V. // Crystallogr. Rep. 2009. V. 54. N 3. P. 492. doi 10.1134/S1063774509030195

[6] Палатников М.Н., Сандлер В.А., Сидоров Н.В., Гурьянов А.В., Калинников В.Т. // ФТТ. 2000. Т. 42. № 8. С. 1456; Palatnikov M.N., Sidorov N.V., Kalinnikov V.T., Sandler V.A., Gur'yanov A.V. // Phys. Sol. St. 2000. V. 42. N 8. P. 1499. doi 10.1134/1.1307061

[7] Сидоров Н.В., Крук А.А., Яничев А.А., Палатников М.Н., Маврин Б.Н. // Опт. и спектр. 2014. Т. 117. № 4. C. 577. doi 10.7868/S0030403414100201; Sidorov N.V., Kruk A.A., Yanichev A.A., Palatnikov M.N., Mavrin B.N. // Opt. Spectrosc. 2014. V. 117. N 4. P. 560.

[8] Ященко А.В., Евдокимов С.В., Палатников М.Н., Сидоров Н.В. // ФТТ. 2019. Т. 61. № 7. С. 1270. doi 10.21883/FTT.2019.07.47836.379; Yatsenko A.V., Evdokimov S.V., Palatnikov M.N., Sidorov N.V. // Phys. Sol. St. 2019. V. 61. N 7. P. 1211. doi 10.1134/1.1307061

[9] Иванов В.И., Карпец, Ю.М., Климентьев С.В. Термостимулированные токи в несимметричной сэндвичной структуре металл-сегнетоэлектрик металл. Хабаровск: ДВГУПС, 2007. 68 с.
[10] Шалдин Ю.В., Габриэлян В.Т., Матыясик С. // Кристаллогр. 2008. T. 53. № 5. C. 896; Shaldin Yu.V., Gabriélyan V.T., Matyjasik S. // Crystallogr. Rep. 2008. V. 53. N 5. P. 847. doi 10.1134/S1063774508050209

[11] Палатников М.Н., Сандлер В.А., Сидоров Н.В., Макарова О.В., Бирюкова И.В., Ефремов И.Н., Иваненко Д.В. // ФТТ. 2015. Т. 57. № 8. С. 1515; Palatnikov M.N., Sandler V.A., Sidorov N.V., Makarova O.V., Biryukova I.V., Efremov I.N., Ivanenko D.V. // Phys. Sol. St. 2015. V. 57. N 8. P. 1541. doi 10.1134/S1063783415080235

[12] Фам Май Ан. Исследование физических аномалий в монокристалле $\mathrm{LiNbO}_{3}$. Автореф. канд. дис. Волгоград, 2014. $17 \mathrm{c}$.

[13] Зазнобин Т.О. Термостимулированные процессы переключения в ниобий содержащих фоторефрактивных сегнетоэлектриках ниобате лития и ниобате бария-стронция. Автореф. канд. дис. Тверь, 2005. 24 с.

[14] Sidorov N., Palatnikov M., Kadetova A. // Crystals. 2019. V. 9. P. 535. doi 10.3390/cryst9100535

[15] Lengyel K., Peter A., Kovacs L., Corradi G., Palfavi L, Hebling J., Unferdorben M., Dravecz G., Hajdara I., Szaller Zs., Polgar K. // Appl. Phys. Rev. 2015. V. 2. P. 040601. doi 10.1063/1.4929917

[16] Shur V.Ya., Akhmatkhanov A.R., Baturin I.S. // Appl. Phys. Rev. 2015. V. 2. P. 040604-1. doi 10.1063/1.4928591

[17] Коханчик Л.С., Палатников М.Н., Щербина О.Б. // ФТТ. 2012. T. 54. № 5. C. 905; Kokhanchik L.S., Palatnikov M.N., Shcherbina O.B. // Phys. Sol. St. 2012. V. 54. N 5. P. 962. doi 10.1134/S1063783412050198

[18] Prokhorov A.M., Kuz'minov Yu.S. Physics and Chemistry of Crystalline Lithium Niobate. Bristol: Adam Hilger, 1990.

[19] Сидоров Н.В., Волк Т.Р., Маврин Б.Н., Калинников В.Т. Ниобат лития: дефекты, фоторефракция, колебательный спектр, поляритоны. М.: Наука, 2003. 255 с.

[20] Volk T., Wohlecke M. Lithium Niobate. Defects, Photorefraction and Ferroelectric Switching. Berlin: Springer, 2008. $250 \mathrm{p}$.

[21] Палатников М.Н., Сидоров Н.В., Стеббанович С.Ю., Калинников В.T. // Неорг. матер. 1998. Т. 34. № 8. С. 903.

[22] Палатников М.Н., Макарова О.В., Сидоров Н.В. Ростовые и технологические дефекты кристаллов ниобата лития различного химического состава. Апатиты: Изд-во КНЦ РАН, 2018. 89 c.

[23] Fontana M.D., Bourson P. // Appl. Phys. Rev. 2015. V. 2. P. 040602-1. doi 10.1063/1.4934203

[24] Ахмадулин И.Ш., Голенищев-Кутузов В.А., Мигачев С.Ф. // ФТТ. 1998. Т. 40. № 6. С. 1109; Akhmadullin I.Sh., Golenishchev-Kutuzov V.A., Migachev S.A. // Phys. Sol. St. 1998. V. 40. N 6. P. 1012. doi 10.1134/1.1130478

[25] Li Y., Li L., Cheng X., Zhao X. // J. Phys. Chem. 2017. V. 121. P. 8968. doi 10.1021/acs.jpcc.7b01274

[26] Блистанов А.А., Любченко В.М., Горюнова А.Н. // Кристаллогр. 1998. Т. 43. № 1. С. 86.

[27] Палатников М.Н., Сидоров Н.В., Бирюкова И.В., Щербина О.Б., Калинников В.Т. // Персп. матер. 2011. № 2. C. 93.

[28] Palatnikov M.N., Biryukova I.V., Sidorov N.V., Denisov A.V., Kalinnikov V.T., Smith P.G.R., Shur V.Ya. // J. Cryst. Growth. 2006. V. 291. P. 390. doi 10.1016/j.jcrysgro.2006.03.022 
[29] Сидоров Н.В., Пикуль О.Ю., Теплякова Н.А., Палатников М.Н. Лазерная коноскопия и фотоиндуцированное рассеяние света в исследованиях свойств нелинейнооптического кристалла ниобата лития. М.: РАН, 2019. $350 \mathrm{c}$.

[30] Caciuc V., Postnikov A.V., Borstel G. // Phys. Rev. B. 2000. V. 61. P. 8806. doi 10.1103/PhysRevB.61.8806

[31] Parlinski K., Li Z.Q., Kawazoe Y. // Phys. Rev. B. 2000. V. 61. P. 272. doi 10.1103/PhysRevB.61.272

[32] Горелик В.С. // Тр. ФИАН. 1982. Т. 132. С. 15.

[33] Palatnikov M.N., Sidorov N.V. // Oxide Electronics and Functional Properties of Transition Metal Oxides. USA: NOVA Sience Publichers, 2014. P. 31.

[34] Svaasand L.O., Erikrund M., Nakken G., Grand A.P. // J. Cryst. Growth. 1974. V. 22. N 3. P. 230. doi 10.1016/00220248(74)90099-2

[35] Сидоров Н.В., Палатников М.Н., Теплякова Н.А., Сюй А.В., Киле E.O., Штарев Д.С. // Неорган. матер. 2018. T. 54. № 6. C. 611. doi 10.7868/S0002337X18060106; Sidorov N.V., Palatnikov M.N., Teplyakova N.A., Syuy A.V., Kile E.O., Shtarev D.S. // Inorg. Mater. 2018. V. 54. N 6. P. 581. doi 10.1134/S0020168518060134

[36] Palatnikov M.N., Manukovskaya D.V., Sidorov N.V., Efremov V.V., Makarova O.V. // Opt. Mater. 2019. V. 90. P. 51. doi 10.1016./j.optmat.2019.02.017

[37] Обуховский В.В. Процессы фоторефрактивного рассеяния света в кристаллах. Автореф. докт. дис. Киев, 1989. 25 с.

[38] Максименко В.А., Сюй А.В., Карпеи, Ю.М. Фотоиндуцированные процессы в кристаллах ниобата лития. М.: Физматлит, 2008. 96 с.

[39] Сидоров Н.В., Антонычева Е.А., Сюй А.В., Палатников М.Н. // Кристаллогр. 2010. Т. 55. № 6. C. 1079; Sidorov N.V., Palatnikov M.N., Antonycheva E.A., Syuı̌ A.V. // Crystallogr. Rep. 2010. V. 55. N 6. P. 1019. doi 10.1134/S1063774510060192

[40] Сидоров Н.В., Палатников М.Н., Калинников В.Т. // ДАН. 2011. T. 441. № 2. C. 209.

[41] Kostritskii S.M., Sevostyanov O.G. // Appl. Phys. B. 1997. V. 65. P. 527. doi $10.1007 / \mathrm{s} 003400050308$ 